\title{
Chitosan-Immobilized Pumice for the Removal of As(V) from Waters
}

\author{
Dilek Turan • Cemre Kocahakimoğlu • Ezel Boyacı • \\ Sait C. Sofuoglu • Ahmet E. Eroğlu
}

Received: 13 November 2013 / Accepted: 10 March 2014

(C) Springer International Publishing Switzerland 2014

\begin{abstract}
A novel sorbent, chitosan-immobilized pumice, has been prepared for the sorption of $\mathrm{As}(\mathrm{V})$ from waters prior to its determination by hydride generation atomic absorption spectrometry. The success of the immobilization has been checked with such characterization techniques as scanning electron microscopy, thermal gravimetric analysis, and elemental analysis. Points of zero charge of the sorbents were determined with potentiometric mass titration. Batch-type equilibration studies have shown that the novel sorbent can be employed at a wide $\mathrm{pH}$ range resulting in quantitative sorption (>90\%) at $\mathrm{pH} 3.0-7.0$ and greater than $70 \%$ sorption at $\mathrm{pH}>8.0$. These results demonstrate the advantage of immobilizing chitosan onto pumice, because, under the same conditions, pumice displays $<20 \%$ sorption toward $\mathrm{As}(\mathrm{V})$, whereas chitosan gives approximately $90 \%$ sorption only at $\mathrm{pH} 3.0$. The validity of the method was verified through the analysis of ultrapure,
\end{abstract}

D. Turan · C. Kocahakimoğlu $\cdot$ S. C. Sofuoglu

Department of Chemical Engineering, İzmir Institute of Technology,

Urla, İzmir 35430, Turkey

E. Boyac1 • A. E. Eroğlu ( $\bowtie)$

Department of Chemistry, İzmir Institute of Technology,

Urla, İzmir 35430, Turkey

e-mail: ahmeteroglu@iyte.edu.tr

S. C. Sofuoglu $(\triangle)$

Environmental Research Center, İzmir Institute of

Technology,

Urla, İzmir 35430, Turkey

e-mail: cemilsofuoglu@iyte.edu.tr bottled drinking, and tap water samples spiked with arsenate; the respective sorption percentages of 93.2 ( \pm 0.7$), 89.0( \pm 1.0)$, and $80.9( \pm 1.3)$ were obtained by batch-type equilibration. Arsenic sorption was also examined in the presence of common interfering ions resulting in competing effects of $\mathrm{PO}_{4}{ }^{3-}$ and $\mathrm{NO}_{3}{ }^{-}$on $\mathrm{As}(\mathrm{V})$ adsorption.

Keywords Arsenic · Chitosan · Pumice - Removal · Biosorbent

\section{Introduction}

Trace metal contamination, especially in water, is a great concern for every living organism, which brings about the need for efficient and environmentally friendly treatment techniques. Among the metal treatment techniques, development of new biosorbents is a significant research area. There are many kinds of recently developed biosorbents for this purpose such as Spirulina platensis (Șeker et al. 2008), Escherichia coli biofilm supported on kaolin (Quintelas et al. 2009), Ulva lactuca (Schijf and Ebling 2010), and carbonate hydroxylapatite (CHAP) prepared from eggshell waste (Zhang et al. 2011).

Among all the biosorbents, chitosan has importance due to its many features like being one of the most abundant natural biopolymers, hydrophilic, nontoxic, biodegradable structure, regeneration, and recycling potential and having the ability to form complexes with metals (Elwakeel 2010; Hasan et al. 2008). As a consequence 
of the last feature, many studies regarding the removal of metal ions from water can be found in the literature. For instance, chitosan hydrogel beads were studied for removal of nitrate (Chatterjee and Woo 2009), and protonated chitosan beads were used for fluoride (Viswanathan et al. 2009). Chaunhan et al. (2012) studied the removal of cadmium and hexavalent chromium from electroplating wastewater using thiocarbamoyl chitosan; Miretzky and Cirelli (2009) studied $\mathrm{Hg}(\mathrm{II})$ removal from water not only by chitosan but also its derivatives; and Chen and Chung (2006) evaluated the removal of As(III) and As(V) from water by chitosan itself due to its excellent biological properties.

Pumice stone is a type of light, highly porous (pore volumes up to $85 \%$ ) (Kitis and Kaplan 2007), and lowcost volcanic stone with high silica content (generally $\left.60-75 \% \mathrm{SiO}_{2}\right)($ Baytak et al. 2008) found abundantly in Turkey. On account of its highly porous structure, it provides a large number of possible attachment sites for pollutants (Alemayehu and Lennartz 2009; Ersoy et al. 2010). Thus, it takes place in environmental applications as supporting material in catalytic removal of trace metals (Baytak et al. 2008; Kitis and Kaplan 2007). It also plays a role as a filtration medium and biofilm support in environmental engineering (Kitis et al. 2005) in addition to its use as a sorbent. For example, Panuccio et al. (2009) concluded that cadmium adsorption on pumice can be performed at $\mathrm{pH} 7.5$ with $90 \%$ efficiency. A sorption of $80 \%$ was reported for $\mathrm{Cu}^{2+}$ and $\mathrm{Cr}^{3+}$ at pH 8.0 and $90 \%$ for cadmium at pH 6.0 (Alemayehu and Lennartz 2009; Yavuz et al. 2008). Asgari et al. (2012) studied fluoride adsorption onto functionalized pumice stone and obtained $96 \%$ removal at $\mathrm{pH} 6$.

As a result of natural and anthropogenic activities, inorganic arsenic is released into natural waters resulting in human exposure via ingestion of contaminated drinking water and foods (Boddu et al. 2008; Choong et al. 2007; Kavcar et al. 2009). Long-term exposures to even very low concentrations have highly toxic effects on human health resulting in skin, lung, liver, kidney, and bladder cancer risks (Boddu et al. 2008; Luu et al. 2009). The World Health Organization (WHO) recommends the standard of arsenic in drinking water as $10 \mu \mathrm{g} \mathrm{L}^{-1}$, and the US, the EU, and Turkey promulgate it (Kavcar et al. 2009).

Although arsenic cannot be destroyed easily, it can be converted into different forms or can be transformed into insoluble compounds in combination with other elements. Arsenic removal is expensive, especially when it coexists with other impurities, such as lead, iron, and selenium (Choong et al. 2007; Hansen et al. 2008). In the arsenic treatment, membrane filtration systems such as reverse osmosis and nanofiltration are very effective; however, those systems have high treatment costs which pose an obstacle for a wide use (Choong et al. 2007). At this point, the need for efficient and cost-effective treatment techniques arises, and adsorption of arsenic onto relatively inexpensive and natural biosorbents is a favorable alternative (Boyac1 et al. 2010; Choong et al. 2007). Sample $\mathrm{pH}$ is an important constraint in arsenic removal by adsorption in a way that depending on the working range of the sorbent used, the solution $\mathrm{pH}$ must be adjusted before, and possibly, after the removal step. For example, the maximum removal of $\mathrm{As}(\mathrm{V})$ with activated carbon was obtained at $\mathrm{pH} 4$ to 5 (Huang and $\mathrm{Fu}$ 1984), while chitosan-coated ceramic alumina was most effective at the $\mathrm{pH}$ of 4 (Boddu et al. 2008). Furthermore, the maximum sorption was obtained at $\mathrm{pH} 3.0$ by Boyac1 et al. (2010) in which chitosan immobilized on sodium silicate was used to remove arsenic. Consequently, there is a lack of sorbents, preferably biosorbents, for a successful sorption of arsenic at the neutral $\mathrm{pH}$ (6 to 8) of drinking water. On the other hand, the presence of interfering ions such as $\mathrm{Mg}^{2+}, \mathrm{Ca}^{2+}, \mathrm{Fe}^{3+}, \mathrm{NO}_{3}{ }^{-}$, and $\mathrm{PO}_{4}{ }^{3-}$ may have competing effects on adsorption of arsenic from natural waters (Kundu et al. 2004; Rau et al. 2003).

The goal of the present study was to develop a biosorbent for arsenic removal from drinking water at neutral $\mathrm{pH}$ levels. Chitosan immobilized on pumice was studied as a new sorbent for this purpose. The characterization of the biomaterial, effects of change in the amount of sorbent, and sorption with respect to time and temperature were investigated. The novel sorbent was also employed in column experiments to investigate the potential of the proposed methodology for further applications. Lastly, interfering effects of some common ions $\left(\mathrm{Mg}^{2+}, \mathrm{Ca}^{2+}, \mathrm{Fe}^{3+}, \mathrm{NO}_{3}{ }^{-}\right.$, and $\left.\mathrm{PO}_{4}{ }^{3-}\right)$ to the adsorption were studied.

\section{Materials and Methods}

\subsection{Reagents}

All chemicals were of analytical reagent grade. Ultrapure water $(18.2 \mathrm{M} \Omega \mathrm{cm})$ was used throughout the study. Glassware and plastic containers were cleaned by soaking in $10 \%(\mathrm{v} / \mathrm{v})$ nitric acid for $24 \mathrm{~h}$ and rinsed with deionized water prior to use. 
Stock standard solutions of $\mathrm{As}(\mathrm{V})$ and $\mathrm{As}(\mathrm{III})$ $\left(2,000.0 \mathrm{mg} \mathrm{L}^{-1}\right)$ were prepared by dissolving $\mathrm{As}_{2} \mathrm{O}_{5}$ (Merck, product code 1.09939, CAS no. [1303-28-2]) and $\mathrm{As}_{2} \mathrm{O}_{3}$ (Fischer, CAS no. [1327-53-3]), respectively, in ultrapure water. Oxalic acid (Carlo Erba, product code 408737, CAS no. [6153-56-6]) solution was prepared in a concentration of $10.0 \%(\mathrm{~m} / \mathrm{v})$ for dissolution of chitosan in immobilization step. Chitosan flakes $(910 \mathrm{kDa})$ were synthesized from practical grade chitin (Sigma, product code C9213, CAS no. [1398-61-4]) by refluxing a mixture of chitin containing $40.0 \%(\mathrm{~m} / \mathrm{m})$ $\mathrm{NaOH}$ (Merck, product code1.06498, CAS no. [131073-2]) solution. L-Cysteine (Merck, product code 1.02838, CAS no. [52-90-4]) was used as a reducing agent for $\mathrm{As}(\mathrm{V})$ to $\mathrm{As}(\mathrm{III})$ prior to arsenic determination by HG-AAS in a concentration of $0.50 \%(\mathrm{~m} / \mathrm{v})$.

The interference studies were carried out with stock solutions of $\mathrm{Mg}\left(\mathrm{NO}_{3}\right)_{2} \cdot 6 \mathrm{H}_{2} \mathrm{O}$ (Merck, product code 1058550050, CAS no. [13446-18-9]), $\mathrm{Ca}\left(\mathrm{NO}_{3}\right)_{2}$. $4 \mathrm{H}_{2} \mathrm{O}$ (Merck, product code 1021230100, CAS no. [13477-34-4]), $\mathrm{Fe}\left(\mathrm{NO}_{3}\right)_{3} \cdot 9 \mathrm{H}_{2} \mathrm{O}$ (Sigma, product code 24855367, CAS no. [7782-61-8] and CAS no. [764714-5]), $\mathrm{HNO}_{3}$ (Sigma, product code 24845344, CAS no. [7697-37-2]), and $\mathrm{H}_{3} \mathrm{PO}_{4}$ (Sigma, product code 24868686, CAS no. [7664-38-2]) in ultrapure water.

\subsection{Preparation of the Chitosan-Immobilized Pumice as a Sorbent}

Chitosan is known to have a tendency to form a gel or agglomerate in aqueous media, and its amine groups are generally considered as main active sites which are responsible for the high adsorption potential for metals (Hasan et al. 2008). In order to increase the adsorption capacity of chitosan, it is widely spread on physical supports that help to enhance the accessibility of metal binding amine sites (Dambies et al. 2002; Elwakeel 2010; Guibal et al. 1998). On the other hand, pumice has a skeleton structure allowing ions and molecules to move and settle with ease. It is a highly preferred support material in many treatment studies due to its rough surface and porous structure which provides various possible attachment sites for pollutants (Alemayehu and Lennartz 2009).

In the light of the experience gained in the previous studies and the literature articles, a novel hybrid sorbent was prepared. First, chitosan flakes were synthesized as it was described elsewhere (Boyac1 et al. 2010). Then, chitosan was immobilized onto pumice with slight modification of the method applied by Boddu et al. (2008) in the immobilization of chitosan onto ceramic alumina. The pumice was taken from Isparta (Turkey) and had a particle size range of $250-1,000 \mu \mathrm{m}$. The acid treatment was required in order to remove organic and inorganic extractable contaminants (Yavuz et al. 2008) which may affect the sorption capacity of the sorbent. In addition, the acid treatment step facilitated the adherence of chitosan onto pumice. For this purpose, $5.0 \mathrm{~g}$ of pumice was stirred with $100 \mathrm{~mL}$ of $10.0 \%(\mathrm{~m} / \mathrm{v})$ oxalic acid for $4 \mathrm{~h}$ at room temperature. Acid-treated pumice was filtered, washed with deionized water until being neutral, and dried in an oven at $70{ }^{\circ} \mathrm{C}$ for $24 \mathrm{~h}$. Supporting particles were further ground to prevent them to settle down from the reaction mixture. In another vessel, chitosan flakes were dissolved in $20.0 \mathrm{~mL}$ of $10.0 \%(\mathrm{~m} / \mathrm{v})$ oxalic acid in order to obtain a $5 \%(\mathrm{~m} / \mathrm{v})$ chitosan solution. To assist the mixing of highly viscous solution, heat was applied at $40-50{ }^{\circ} \mathrm{C}$ until a clear solution was observed as a result of complete dissolution of flakes. About $5.0 \mathrm{~g}$ of the acidtreated pumice was added slowly to the diluted gel and stirred for $2 \mathrm{~h}$ at the same mixing temperature. Excess oxalic acid in the composite biosorbent was neutralized by the addition of 1.0 M NaOH solution followed by filtration and washing with deionized water until a neutral filtrate was obtained. After the immobilization procedure, the chitosan-immobilized pumice was dried at $60{ }^{\circ} \mathrm{C}$ overnight and ground by mortar and pestle prior to use.

\subsection{Characterization Studies}

Various methods were applied for the characterization of pumice, synthesized chitosan flakes, and chitosanimmobilized pumice. The elemental compositions of the sorbents were determined by a LECO-CHNS-932 elemental analyzer (Mönchengladbach, Germany). For determination of the degree of deacetylation, potentiometric titrimetry and elemental analysis were employed as described elsewhere (Tolaimate et al. 2000). Images of pumice, chitosan, and chitosan-immobilized pumice were obtained with a Philips XL-30S FEG scanning electron microscope (SEM) (Eindhoven, The Netherlands). In addition, thermal gravimetric degradation behavior was examined with PerkinElmer Pyris Diamond TG/DTA (Boston, MA, USA). Particle size distribution of oxalic-acid-treated pumice and chitosan-immobilized pumice was determined by Mastersizer 2000 and Hydro 2000S (Malvern Worcs, UK). Point of zero charge (PZC) for pumice and the novel sorbent were 
determined with a potentiometric mass titration method (Bourikas et al. 2003).

\subsection{Sorption Studies}

Sorption studies were performed for all the sorbents through batch process. Solution $\mathrm{pH}$ was adjusted with inoLab Level $1 \mathrm{pH}$ meter (Weilheim, Germany) using various concentrations of $\mathrm{HCl}$ and $\mathrm{NH}_{3}$. The batch sorption studies were carried out in GFL 1083 water bath shaker (Burgwedel, Germany) equipped with a microprocessor thermostat. Effect of solution $\mathrm{pH}$, amount of sorbent, reaction time, ionic strength, and reaction temperature were investigated. Investigated parameters are summarized in Table 1. Batch sorption was followed by filtration of the mixture through blue-band filter paper. Each sorption was achieved in triplicate trials. All samples and standard solutions were acidified with concentrated $\mathrm{HCl}$ to produce $1.0 \%(v / v) \mathrm{HCl}$ in the final solution. A Thermo Elemental SOLAAR M6 Series atomic absorption spectrometer (Cambridge, UK) with an airacetylene burner was used in arsenic determination utilizing the segmented flow injection hydride generation (SFI-HGAAS) unit. An arsenic hollow cathode lamp $(193.7 \mathrm{~nm})$ and a deuterium lamp were employed as the source line and for background correction, respectively. Operating parameters for the HGAAS system were as follows: $200 \mathrm{~mL} \mathrm{~min}^{-1}$ carrier gas $\left(\mathrm{N}_{2}\right)$ flow rate, $6.1 \mathrm{~mL} \mathrm{~min}^{-1} \mathrm{HCl}$ flow rate, $2.0 \%(v / v) \mathrm{HCl}$ concentration, $3.0 \mathrm{~mL} \mathrm{~min}^{-1} \mathrm{NaBH}_{4}$ flow rate, $1.0 \%(m / v) \mathrm{NaBH}_{4}$ concentration (stabilized with $0.1 \%(m / v) \mathrm{NaOH})$, and $7-$

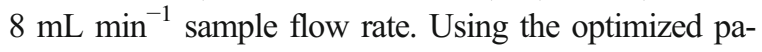
rameters, calibration equation was $y=0.0046 \mathrm{x}+0.0278$, $R^{2}=0.992$; limit of detection $\left(\mathrm{LOD}_{3 \mathrm{~s}}\right)$ and limit of quantification (LOQ) were 0.79 and $2.61 \mu \mathrm{g} \mathrm{L}^{-1}$, respectively.

Interfering effects of selected ions during the removal of $\mathrm{As}(\mathrm{V})$ were examined under optimized sorption

Table 1 Summary of the parameters and ranges used throughout the study

\begin{tabular}{ll}
\hline Parameters investigated & Range \\
\hline pH of solution & $2.0,3.0,4.0,6.0,7.0,8.0$, and 10.0 \\
Amount of sorbent (mg) & $25.0,50.0,75.0,100.0,150.0$, \\
& 200.0, and 250.0 \\
Reaction time (min) & $15,30,60,120,240,360$, and 720 \\
Ionic strength (M of $\mathrm{NaCl})$ & $0.0001,0.001$, and 0.01 \\
Sorption temperature $\left({ }^{\circ} \mathrm{C}\right)$ & 25,50, and 75 \\
\hline
\end{tabular}

conditions. For this purpose, 15 solutions ( $\mathrm{pH} 7.0$ ), all of them containing $100.0 \mu \mathrm{g} \mathrm{L}^{-1} \mathrm{As}(\mathrm{V})$ and varying amount of each interfering ion (with $100.0 \mu \mathrm{g} \mathrm{L}^{-1}$ $\mathrm{As}(\mathrm{V})$ solutions in separate medium containing $0.1,1$, and $10 \mathrm{mg} \mathrm{L}^{-1}$ ), were prepared separately and used in sorption study.

\subsection{Application to Natural Samples}

In order to demonstrate the applicability of the developed method, two natural water samples were chosen, namely, commercial bottled spring water and tap water from the campus of İzmir Institute of Technology (IZTECH), Urla, İzmir. Each sample was spiked with $100.0 \mu \mathrm{g} \mathrm{L}^{-1}$ arsenate. Solution volume, sorbent amount, solution $\mathrm{pH}$, and reaction temperature were $20.0 \mathrm{~mL}, 200.0 \mathrm{mg}, 7.0$, and $25^{\circ} \mathrm{C}$, respectively.

\subsection{Column Application}

In order to show the applicability of chitosanimmobilized pumice in the continuous removal of arsenic from water, the column sorption was also carried out. A 50-mm height FEP tubing with internal diameter of $1.5 \mathrm{~mm}$ was used in the preparation of microcolumns. The particle size of the chitosan-immobilized pumice was sieved to a range of $125-150 \mu \mathrm{m}$. The microcolumn was filled with the sorbent to obtain $25-\mathrm{mm}$ active filling. The $100.0 \mu \mathrm{g} \mathrm{L}^{-1} \mathrm{As}(\mathrm{V})$ solution was passed through the column in an upward flow at a flow rate of $0.8 \mathrm{~mL} \mathrm{~min}^{-1}$ using a peristaltic pump. In addition to spiked ultrapure water, spiked tap water samples from IZTECH campus were also used. The effluent was collected in $1.0-\mathrm{mL}$ volume intervals.

\section{Results and Discussion}

\subsection{Characterization Studies}

The amount of acetyl groups removed from a starting material (chitin) in terms of the degree of deacetylation was determined as $87.3 \%$ by potentiometric titrimetry (Tolaimate et al. 2000). This result is in agreement with the result of the elemental analysis $(84.7 \%)$. The elemental compositions of chitosan, pumice, and chitosanimmobilized pumice are summarized in Table 2. The elemental analysis results are not only indicative of deacetylation process but also valuable for determining 
Table 2 Results of the elemental analysis

\begin{tabular}{llll}
\hline \multicolumn{4}{c}{$\%$} \\
\hline Sorbent & $\mathrm{N}$ & $\mathrm{C}$ & $\mathrm{H}$ \\
Pumice & 0.00 & 0.26 & 0.62 \\
Chitosan-immobilized pumice & 0.60 & 3.78 & 1.19 \\
Chitosan & 7.55 & 40.8 & 7.23 \\
\hline
\end{tabular}

the amount of chitosan immobilized onto pumice. The ratio of carbon percentage of chitosan-immobilized pumice to that of chitosan indicates that $9.3 \%$ of the material was immobilized onto pumice. This value is also in accordance with the amount determined gravimetrically after calcination of the chitosan-immobilized pumice $(11.3 \%)$.

SEM images of pumice, chitosan, and chitosanimmobilized pumice can be seen in Fig. 1. As shown, pumice is highly porous as compared with chitosan. The image of chitosan-immobilized pumice indicates that chitosan was well dispersed on the surface of pumice stone, and this high degree of dispersion must have increased the available surface active sites of chitosan which are responsible for sorption.

TGA of the sorbents was carried out by flowing $\mathrm{N}_{2}$ gas from room temperature to $800{ }^{\circ} \mathrm{C}$. It can be seen from Fig. 2 that weight is gradually decreased to almost $0 \%$ in the case of chitosan. The weight loss between 25 and $97{ }^{\circ} \mathrm{C}$ can be ascribed to the removal of water molecules adsorbed on the surface, whereas smaller weight loss between 98 and $266^{\circ} \mathrm{C}$ is due to the elimination of bonded water. Weight loss owing to the thermal degradation of chitosan took place between 266 and $800{ }^{\circ} \mathrm{C}$. However, within the same temperature range, pumice had a very small weight loss ( $5 \%$ ), possibly through the decomposition of organic contaminants. The thermal behavior of chitosan-immobilized pumice was between chitosan and pumice in a way that water was lost up to $244{ }^{\circ} \mathrm{C}$, resulting in a $15 \%$ weight loss (Fig. 2); yet, at higher temperatures, small changes in the weight were due to the decomposition of chitosan in the composite structure leaving pumice itself.

Original particle size of pumice was in the range of $250-1,000 \mu \mathrm{m}$. This wide range of particle size precluded its direct use due to difficulties in getting homogeneous amount of chitosan in final sorbent. Therefore, an average particle size of $143 \mu \mathrm{m}$ was obtained through milling after oxalic acid treatment. A final grinding of bulk chitosan-immobilized pumice resulted in an average particle size of $81 \mu \mathrm{m}$.

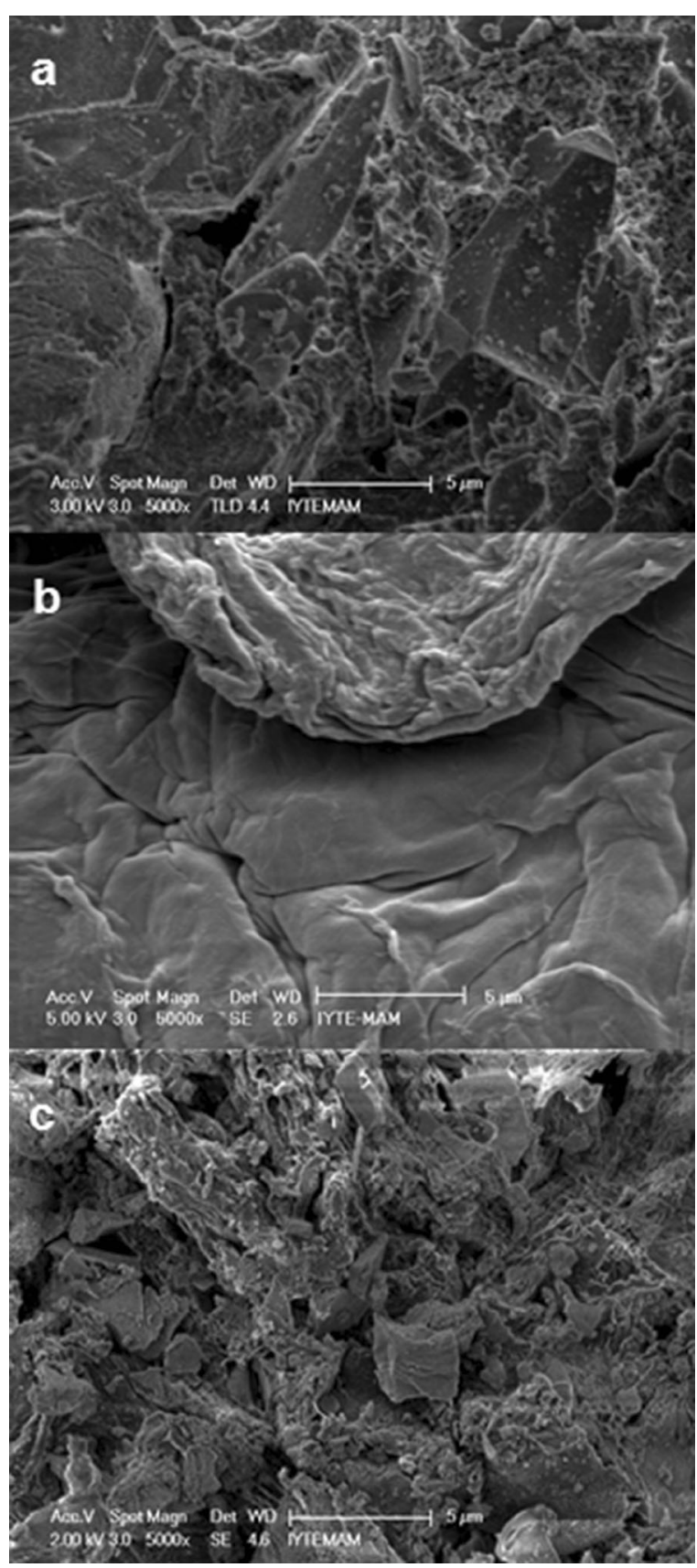

Fig. 1 SEM images of a pumice, $\mathbf{b}$ chitosan, and $\mathbf{c}$ chitosanimmobilized pumice

PZCs of chitosan-immobilized pumice and pumice were determined by application of potentiometric mass titration as described by Bourikas et al. (2003). After application of the aforementioned method, the PZCs of pumice and chitosanimmobilized pumice were determined to be about 6.8 and 7.4 , respectively. 
Fig. 2 TGA curves of a pumice, b chitosan-immobilized pumice, and $\mathbf{c}$ chitosan

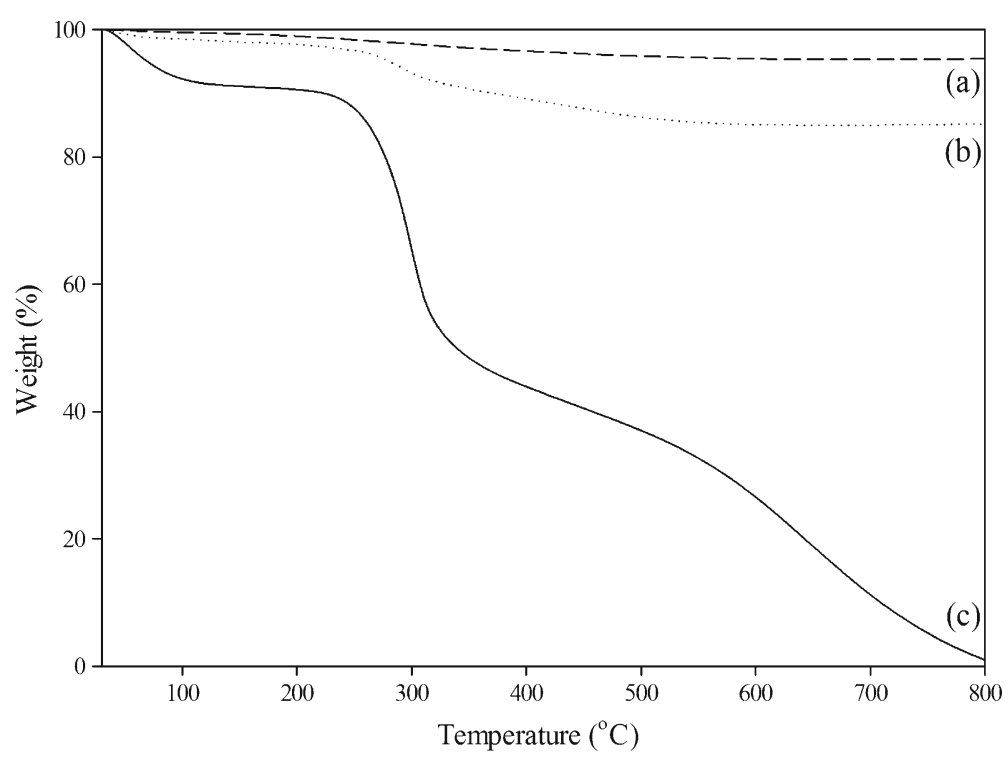

\subsection{Sorption Studies}

\subsubsection{Effect of $p H$ on the Sorption of $A s(V)$ and As(III)}

A review of the literature has shown that chitosan-immobilized pumice was not subjected to investigation as a sorbent for water treatment previously. In this study, initial experiments were carried out to investigate sorption characteristics of newly prepared chitosan-immobilized pumice as well as pumice and chitosan itself by the variation in solution $\mathrm{pH}$. The sorption results for $\mathrm{As}(\mathrm{V})$ and $\mathrm{As}(\mathrm{III})$ as a function of solution $\mathrm{pH}$ are given in Fig. 3. As shown in Fig. 3a, pumice was not able to efficiently remove $\mathrm{As}(\mathrm{V})$ from the solution at any $\mathrm{pH}$ tested. The relatively low sorption (0-20\%) of pumice can be attributed to the presence of minor amounts of $\mathrm{Al}_{2} \mathrm{O}_{3}(16.6 \%)$ and $\mathrm{Fe}_{2} \mathrm{O}_{3}(4.8 \%)$ since these compounds, namely, activated alumina-based sorbents and iron oxide-based nanoparticles, in addition to hybrid materials and commercial resins, have been employed as sorbents for removal of inorganic arsenic species. In contrast to pumice, chitosan was very effective in the sorption of $\mathrm{As}(\mathrm{V})$ only at a specific $\mathrm{pH}$ of 3.0, as already been demonstrated in our previous study (Boyac1 et al. 2010). The specific sorption was explained to be due to the electrostatic attraction between the positively charged surface active groups on chitosan (protonated amine groups) and $\mathrm{H}_{2} \mathrm{AsO}_{4}{ }^{-}$ion, the predominant (about $85 \%$ ) As(V) species at $\mathrm{pH}$ 3.0. The PZC of chitosan is about 6.3, and under this $\mathrm{pH}$, amine groups of chitosan are protonated. Lowering the $\mathrm{pH}$ strongly increases the positive charge on the surface which supports the electrostatic nature of sorption (Boddu et al. 2008; Boyac1 et al. 2010). The use of more acidic conditions is not recommended because of the possibility of dissolution of chitosan flakes.

In contrast to chitosan, chitosan-immobilized pumice displayed different, more efficient sorption behavior in a way that this novel sorbent can be applied at a wider $\mathrm{pH}$ range, from 3.0 to 7.0 ( $\geq 90 \%$ removal). The sorbent can also be used between pHs 7.0 and 10.0 with a percent sorption of about $75 \pm 10$. The sorption characteristics of the novel sorbent toward $\mathrm{As}(\mathrm{V})$ are completely distinctive from chitosan or pumice which suggest a predominant chelation of arsenate between chitosan functional groups and pumice surface active sites. In addition, Mohan and Pittman (2007) stated that Al-hydroxide presence in the surface of adsorbents may be responsible for arsenic sorption at a wide $\mathrm{pH}$ range.

In the case of $\mathrm{As}(\mathrm{III})$, neither pumice nor chitosan was capable of removal $(<20 \%)$ from solutions under the working conditions (Fig. 3b). However, chitosan-immobilized pumice showed around $50 \pm 10 \%$ affinity for arsenite between pHs 3.0 and 8.0 where the predominant species is neutral $\mathrm{H}_{3} \mathrm{AsO}_{3}$. Above $\mathrm{pH} 9.0$ to 13.0 , $\mathrm{As}(\mathrm{III})$ 
Fig. 3 Effect of $\mathrm{pH}$ on the sorption of $100.0 \mu \mathrm{g} \mathrm{L}^{-1}$ of a $\mathrm{As}(\mathrm{V})$ and $\mathbf{b} \mathrm{As}(\mathrm{III})$. The circles, triangles, and squares denote chitosan-immobilized pumice, pumice, and chitosan, respectively (reaction time $4 \mathrm{~h}$, sorbent amount $200.0 \mathrm{mg}$, sample volume $20.0 \mathrm{~mL}$, sorption temperature $25^{\circ} \mathrm{C}, n=3$ )
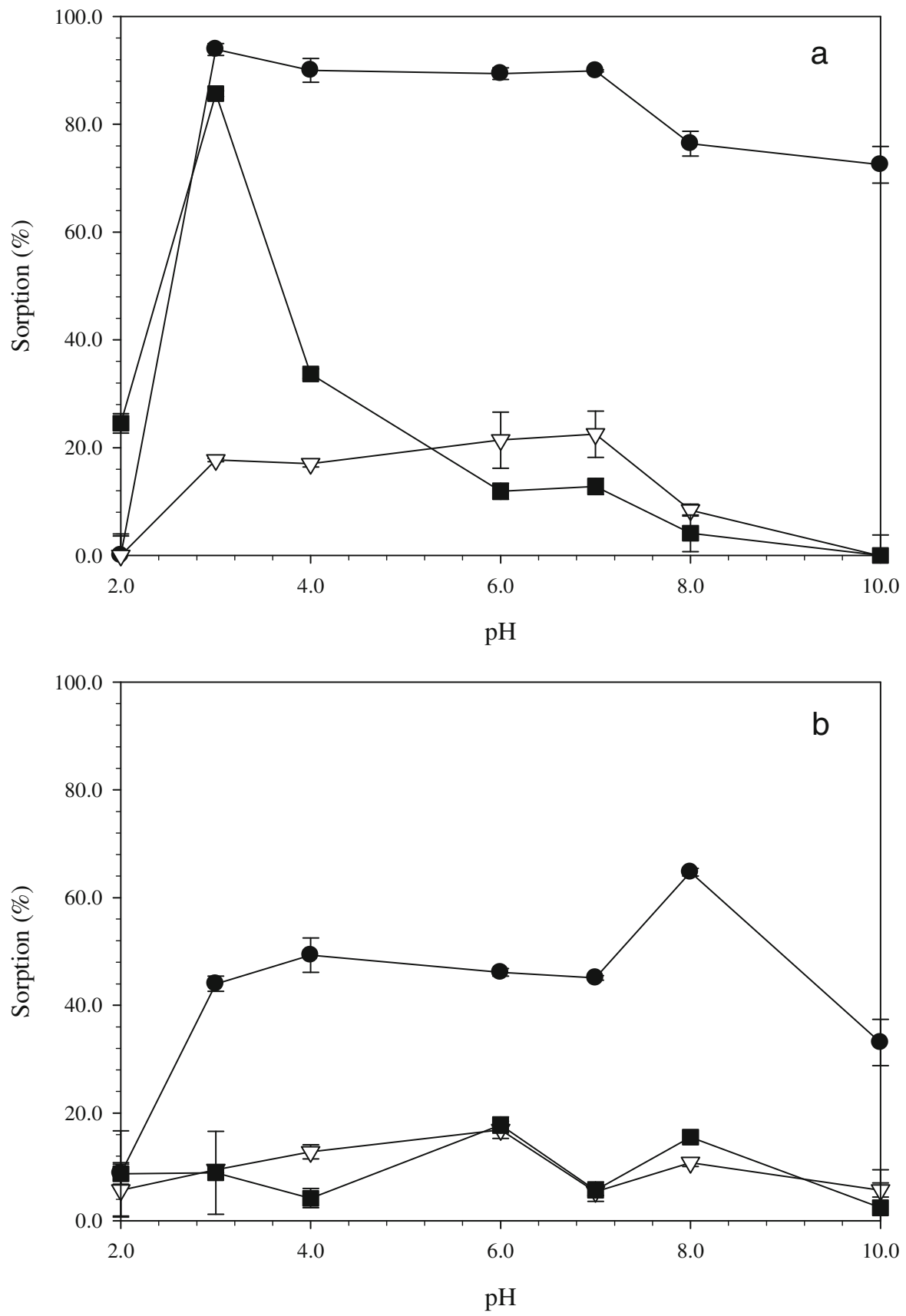

is in the form of $\mathrm{H}_{2} \mathrm{AsO}_{3}{ }^{-}$, and the sorption decreased below $40 \%$ at $\mathrm{pH} 10.0$. At any particular point in the studied $\mathrm{pH}$ range, the arsenite species cannot display electrostatic interaction with the sorbent. However, some hydroxyl groups present in the biosorbent may be involved in the coordination with the sorbate. Lower arsenite sorption was also reported by Boddu et al. (2008) and
Chen et al. (2008), who suggested the interaction of arsenite with the unprotonated amine groups. Furthermore, decrease in the sorption capacity of As(III) for $\mathrm{pH}>7.5$ may be resulted from the competition of $\mathrm{OH}^{-}$ions for the sorption sites, and the reversal of the surface charge of the sorbent may also be possible (Maliyekkal et al. 2009). 
As can be followed from the previous discussion, the high efficiency (greater than $90 \%$ sorption) of the novel sorbent toward $\mathrm{As}(\mathrm{V})$ between pHs 3.0 and 7.0 offers an important advantage since it removes the possible $\mathrm{pH}$ adjustment step before the application of the new methodology unless the solution $\mathrm{pH}$ is either too high or too low. Especially at the approximate $\mathrm{pH}$ of natural waters, the novel sorbent can directly be applied without $\mathrm{pH}$ adjustment. Even for As(III), less probable form of the arsenic in surface waters, greater than $40 \%$ removal, can be considered to be another advantage of the method. In order for the sorbent to be more applicable for removal of arsenate from natural water, the $\mathrm{pH}$ of 7.0 was chosen for further optimization studies.

\subsubsection{Effect of the Sorbent Amount on the Sorption of $A s(V)$}

The effect of the sorbent amount on $\operatorname{As}(\mathrm{V})$ sorption is demonstrated in Fig. 4. It was found that as the amount of sorbent increased, the sorption also increased. The maximum sorption was reached at the investigated highest amount of $250.0 \mathrm{mg}$; however, increasing the amount from 75.0 to $250.0 \mathrm{mg}$ did not have a critical effect on the sorption. This was an indication of the adequacy of the active sites for sorption even though the chitosan-immobilized pumice had only $10 \%(\mathrm{~m} / \mathrm{m})$ chitosan. This finding is essential for probable application of the novel sorbent for municipal water treatment since pumice has the advantage of being a low-cost and naturally abundant material.

\subsubsection{Effect of the Reaction Time on the Sorption of $A s(V)$}

The effect of reaction (equilibration) time on the sorption of arsenate by chitosan-immobilized pumice was investigated for different time intervals from $15 \mathrm{~min}$ to $12 \mathrm{~h}$. As can be seen from Fig. 5, the optimum equilibration time for $\mathrm{As}(\mathrm{V})$ removal was determined as $240 \mathrm{~min}(4 \mathrm{~h})$. However, a significant sorption of $60 \%$ was observed even in 15-min sorption time.

\subsubsection{Effect of the Temperature on the Sorption of As(V) and Sorption Isotherm}

In order to examine the effect of the reaction temperature on $\mathrm{As}(\mathrm{III})$ and $\mathrm{As}(\mathrm{V})$ sorption, three different temperatures, 25,50 , and $75^{\circ} \mathrm{C}$, were applied. The respective sorption percentages of 93,88 , and $74 \%$ were obtained for $\mathrm{As}(\mathrm{V})$.

Thermodynamic parameters of sorption $\left(\Delta \mathrm{G}^{\circ}\right.$, $\Delta \mathrm{S}^{\circ}$, and $\Delta \mathrm{H}^{\circ}$ ) were calculated using the wellknown equations (Atkins and de Paula 2002) for standard Gibbs free energy change (Eq. (1)), standard enthalpy change (Eq. (2)), and standard entropy change (Eq. (3)) for the reaction. Where, $R_{d}$ $\left(\mathrm{mL} \mathrm{g}^{-1}\right)$ is the ratio of arsenate ions distributed at equilibrium between sorbent $\left(\mathrm{mg} \mathrm{g}^{-1}\right)$ and aqueous
Fig. 4 Effect of sorbent amount on the sorption of $100.0 \mu \mathrm{g} \mathrm{L}^{-1}$ $\mathrm{As}(\mathrm{V})$ (reaction time $4 \mathrm{~h}$, sample $\mathrm{pH} 7.0$, sample volume $20.0 \mathrm{~mL}$, sorption temperature $25^{\circ} \mathrm{C}, n=3$ )

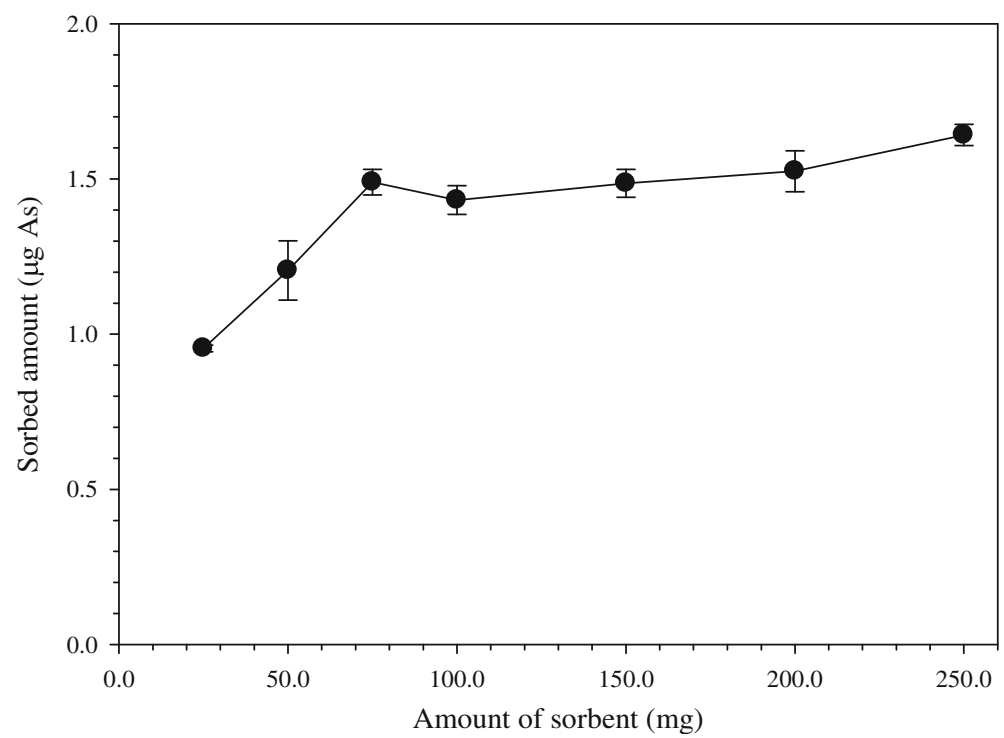


Fig. 5 Effect of reaction time on sorption of $100.0 \mu \mathrm{g} \mathrm{L}^{-1} \mathrm{As}(\mathrm{V})$ (sorbent amount $200.0 \mathrm{mg}$, sample $\mathrm{pH} 7.0$, sample volume $20.0 \mathrm{~mL}$, sorption temperature $25^{\circ} \mathrm{C}, n=3$ )

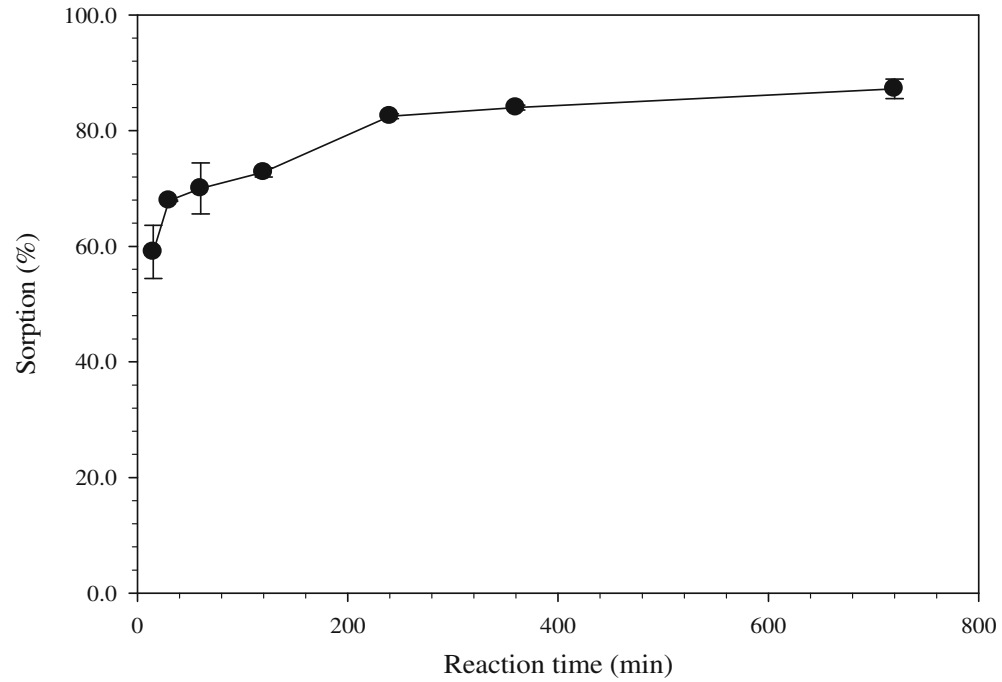

solution of arsenate $\left(\mathrm{mg} \mathrm{L}^{-1}\right)$ which is in contact with the sorbent (Eq. (4)).

$\Delta \mathrm{G}^{\circ}=-R T \ln R_{d}$

$\Delta \mathrm{H}^{\circ}=R \ln \frac{R_{d\left(T_{2}\right)}}{R_{d\left(T_{1}\right)}}\left(\frac{1}{T_{1}}-\frac{1}{T_{2}}\right)^{-1}$

$\Delta \mathrm{S}^{\circ}=\frac{\Delta \mathrm{H}^{\circ}-\Delta \mathrm{G}^{\circ}}{T}$

$R_{d}=\frac{C_{\text {sorbent }}}{C_{\text {samplesolution }}}$

According to the thermodynamic parameters given in Table 3, the sorption of arsenate by chitosanimmobilized pumice is spontaneous at low temperatures. The exothermic nature of the arsenate sorption by chitosan-immobilized pumice can be understood from the negative $\Delta \mathrm{H}^{\circ}$ value. On the other hand, any significant effects for As(III) sorption with respect to temperature change were not observed.
For further clarification of arsenic sorption by proposed sorbent, Dubinin-Radushkevich (D-R) isotherm model was used. The details of the isotherm model were explained in our previous study (Boyac1 et al. 2010). The linear correlation of the model is 0.995 suggesting that the isotherm is suitable to describe the sorption of $\mathrm{As}(\mathrm{V})$ by the sorbent. In a typical sorption study, the arsenic amount adsorbed was $0.0066 \mathrm{mg}$ As per gram sorbent (initial concentration of As $100.0 \mu \mathrm{g} \mathrm{L}^{-1}$, solution volume $20.0 \mathrm{~mL}$, and sorbent amount $250.0 \mathrm{mg}$ ) and according to the maximum sorption capacity (0.3697 mg As per gram sorbent), calculated from linearized form of the isotherm, only small portion of the sorbent capacity appears to be used for sorption, and sorbent is far away from saturation. In addition, the calculated value of mean free energy of sorption $\left(3.45 \mathrm{~kJ} \mathrm{~mol}^{-1}\right)$ is indicative of physisorption.

\subsubsection{Effect of Interfering Ions on the Sorption of $A s(V)$}

Effect of the possible interfering ions to sorption of As(V) was studied and shown in Table 4. The sorption percentages for $\mathrm{As}(\mathrm{V})$ in the presence of interfering ions

Table 3 Thermodynamic parameters of chitosan-immobilized pumice

\begin{tabular}{llllll}
\hline & $\Delta \mathrm{G}\left(\mathrm{kJ} \mathrm{mol}^{-1}\right)$ & & $\Delta \mathrm{H}\left(\mathrm{kJ} \mathrm{mol}^{-1}\right)$ & \multicolumn{2}{c}{$\Delta \mathrm{S}\left(\mathrm{J} \mathrm{mol}^{-1} \mathrm{~K}^{-1}\right)$} \\
\hline & $298 \mathrm{~K}$ & $323 \mathrm{~K}$ & & $298 \mathrm{~K}$ & $323 \mathrm{~K}$ \\
Chitosan-immobilized pumice & -17.9 & -17.7 & -19.7 & -6.2 & -6.2 \\
\hline
\end{tabular}

$\mathrm{As}(\mathrm{V})$ concentration $100.0 \mu \mathrm{g} \mathrm{L}-1$, reaction time $4 \mathrm{~h}$, sorbent amount $200.0 \mathrm{mg}$, sample $\mathrm{pH} 7.0$, sample volume $20.0 \mathrm{~mL}, n=3$ 
Table 4 Effects of interfering ions on $\mathrm{As}(\mathrm{V})$ adsorption

\begin{tabular}{llll}
\hline & & $0.1 \mathrm{mg} \mathrm{L}^{-1} \mathrm{As}(\mathrm{V})$ \\
\hline Interfering ion & $0.1 \mathrm{mg} \mathrm{L}^{-1}$ & $1 \mathrm{mg} \mathrm{L}^{-1}$ & $10 \mathrm{mg} \mathrm{L}^{-1}$ \\
$\mathrm{Mg}^{2+}$ & $\mathrm{N}$ & $\mathrm{N}$ & $\mathrm{N}$ \\
$\mathrm{Ca}^{2+}$ & $\mathrm{N}$ & $\mathrm{N}$ & $\mathrm{N}$ \\
$\mathrm{Fe}^{3+}$ & $\mathrm{N}$ & $\mathrm{N}$ & $\mathrm{N}$ \\
$\mathrm{NO}_{3}{ }^{-}$ & $\mathrm{I}$ & $\mathrm{I}$ & $\mathrm{I}$ \\
$\mathrm{PO}_{4}{ }^{3-}$ & $\mathrm{I}$ & $\mathrm{I}$ & $\mathrm{I}$ \\
\hline
\end{tabular}

$\mathrm{As}(\mathrm{V})$ concentration $100.0 \mu \mathrm{g} \mathrm{L} \mathrm{L}^{-1}$, reaction time $4 \mathrm{~h}$, sorbent amount $200.0 \mathrm{mg}$, sample $\mathrm{pH} 7.0$, sample volume $20.0 \mathrm{~mL}, n=3$

$N$ no interference, $I$ interference

were determined and compared with the sorption percentage of $\mathrm{As}(\mathrm{V})$ in interference free case. Any positive or negative deviation greater than $20 \%$ was considered as a criterion for interference. The results showed that the cations, $\mathrm{Mg}^{2+}, \mathrm{Ca}^{2+}$, and $\mathrm{Fe}^{3+}$, used in this study did not show interference effect. Chloride ion was not examined as possible interference in this particular study; however, the ionic strength studies have demonstrated noninterfering effects for this ion (Sect. 3.3). On the other hand, $\mathrm{NO}_{3}{ }^{-}$and $\mathrm{PO}_{4}{ }^{3-}$ ions had interfering effects at all concentrations tested. The affinity of the novel sorbent to $\mathrm{PO}_{4}{ }^{3-}$ and $\mathrm{NO}_{3}{ }^{-}$was similar to the results obtained by Rau et al. (2003).

\subsection{Application to Natural Samples}

Natural waters spiked with arsenate were used to show the applicability of the proposed method to real samples.
Percentage sorption values were $93.2( \pm 0.7)$ for the ultrapure, $89.0( \pm 1.0)$ for the bottled drinking, and $80.9( \pm 1.3)$ for the tap water samples. The small decrease in the sorption for tap water can be attributed to the presence of competitive ions for the active sites of the sorbent. However, the decrease was tolerable which was also supported by the ionic strength study (results are not given) where no significant effect was observed in the sorption characteristics of chitosan-immobilized pumice even after the addition of $0.01 \mathrm{M} \mathrm{NaCl}$. This is especially important for the application of the novel sorbent to the natural waters that have variable ionic concentrations.

\subsection{Column Application}

In addition to the batch equilibration studies, the potential use of the chitosan-immobilized pumice was also tried in column equilibration. The sorption was studied with both ultrapure and tap water after spiking with As(V). Each milliliter of the effluent collected off the column was analyzed for its As(V) concentration (Fig. 6). As can be seen from the figure, there was a gradual decrease in the sorption of $\mathrm{As}(\mathrm{V})$ from the ultrapure water. It was stabilized around $60 \%$ after $18 \mathrm{~mL}$. The results obtained with tap water were more efficient in contrast to the results obtained in batch sorption. The sorption was greater than $95 \%$ even at the 15 th fraction, and it was decreased to around $90 \%$ at the 20th fraction. The higher sorption obtained with tap water can be due to the stabilization of the arsenate in tap water matrix. The increase in the sorption percentages obtained in the column study as compared
Fig. 6 Microcolumn sorption of $100.0 \mu \mathrm{g} \mathrm{L}^{-1} \mathrm{As}(\mathrm{V})$. Sorption (\%) scale: tap water (black circles) and ultrapure water (white circles); $\mu \mathrm{g} \mathrm{As} \mathrm{g}^{-1}$ sorbent scale: tap water (black squares) and ultrapure water (white squares) (flow rate $0.8 \mathrm{~mL} \mathrm{~min}^{-1}$, particle size $125-150 \mu \mathrm{m}$, active column height $24 \mathrm{~mm}$, column diameter $1.6 \mathrm{~mm}$, sample $\mathrm{pH} 7.0$, sample volume $20.0 \mathrm{~mL}$, sorption temperature $25^{\circ} \mathrm{C}$ )

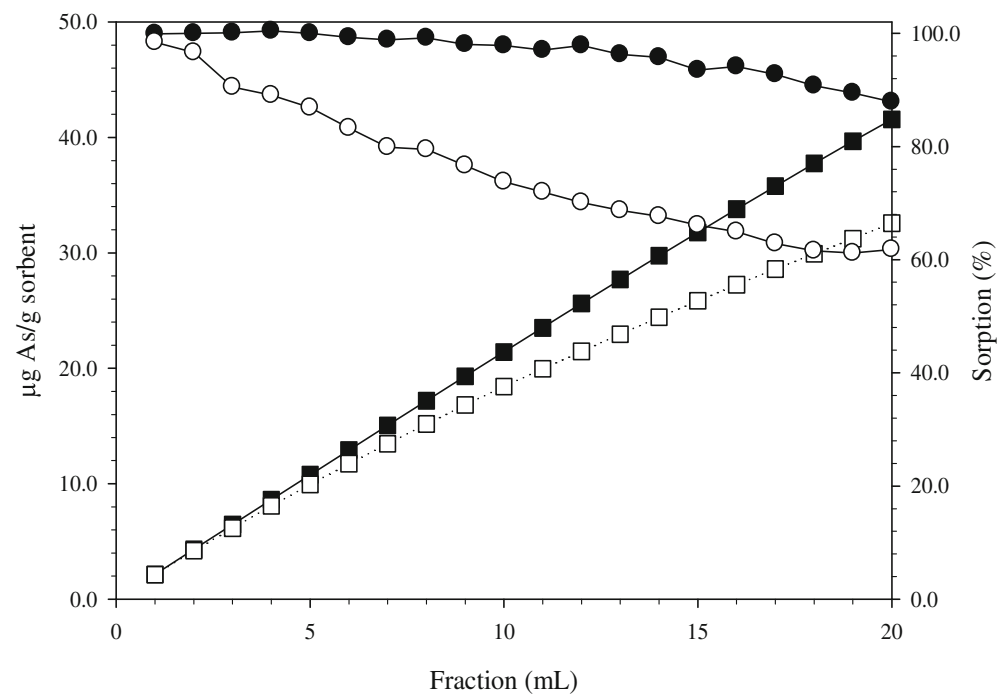


with the batch can be attributed to the different mechanisms of the sorption and to the differences in the contact time of sorbent and analyte in the two equilibration modes. The relatively long $(4 \mathrm{~h})$ sorption time applied in the batch sorption might have resulted in the dissolution of some minerals from pumice affecting the sorption capacity. This observation can be a topic of further studies. As a conclusion, it can be argued that the application of the novel sorbent in the column mode indicates a potential for simpler water treatment systems.

In addition, a preliminary desorption study was carried out with $1 \%(\mathrm{~m} / \mathrm{v})$ L-cysteine solution in order to evaluate regeneratibility of the novel sorbent. L-Cysteine is a well-known reducing agent that can reduce the adsorbed As(V) to As(III). Thus, in the presence of Lcysteine, retained $\mathrm{As}(\mathrm{V})$ is converted to weakly adsorbed As(III). As a consequence, $80 \%$ desorption was obtained which is promising for reusability of the sorbent. However, no further evaluation was performed since the sorbent is designed for single use.

\section{Conclusions}

It has been shown that chitosan-immobilized pumice can be applied in quantitative ( $>90 \%$ ) sorption of $\mathrm{As}(\mathrm{V})$ from the waters at neutral $\mathrm{pHs}$. In addition, a wide $\mathrm{pH}$ range (3.0-10.0) can be used for arsenate sorption by chitosan-immobilized pumice in contrast to chitosan whose sorption was limited only to $\mathrm{pH}$ 3.0. The nature of the sorption of chitosan was considered to be electrostatic in nature; however, in the case of chitosan-immobilized pumice, chelate formation mechanism can be more appropriate. Optimized sorption parameters for the batch system were as follows: solution $\mathrm{pH}$ of 7.0, sorbent amount of $200 \mathrm{mg}$, reaction temperature of $25^{\circ} \mathrm{C}$, and reaction time of $4 \mathrm{~h}$. Sorption of $\mathrm{As}(\mathrm{V})$ decreased with the increase in solution temperature which indicates the exothermic nature of the sorption. Use of the novel sorbent in the column mode has demonstrated its potential for use in water treatment.

Acknowledgments The authors thank the Center of Material Research for the facilities SEM and TGA, Environmental Research Center for ICP-MS analyses in preliminary studies at İzmir Institute of Technology. Prof. Dr. Hürriyet Polat for particle size determination, Dr. Hüseyin Özgener for elemental analysis, and Prof. Dr. Mehmet Kitis at Suleyman Demirel University (Turkey) for kindly providing the pumice samples are also acknowledged.

\section{References}

Alemayehu, E., \& Lennartz, B. (2009). Virgin volcanic rocks: kinetics and equilibrium studies for the adsorption of cadmium from water. Journal of Hazardous Materials, 169, 395401.

Asgari, G., Roshani, B., \& Ghanizadeh, G. (2012). The investigation of kinetic and isotherm of fluoride adsorption onto functionalize pumice stone. Journal of Hazardous Materials, 217-218, 123-132.

Atkins, P., \& de Paula, J. (2002). Atkins' physical chemistry. New York: Oxford University Press.

Baytak, S., Kenduzler, E., Turker, A. R., \& Gok, N. (2008). Penicillium digitatum immobilized on pumice stone as a new solid phase extractor for preconcentration and/or separation of trace metals in environmental samples. Journal of Hazardous Materials, 153, 975-983.

Boddu, V. M., Abburi, K., Talbott, J. L., Smith, E. D., \& Haasch, R. (2008). Removal of arsenic (III) and arsenic (V) from aqueous medium using chitosan-coated biosorbent. Water Research, 42, 633-642.

Bourikas, K., Vakros, J., \& Kordulis, C. (2003). Potentiometric mass titrations: experimental and theoretical establishment of a new technique for determining the point of zero charge (PZC) of metal (hydr)oxides. Journal of Physical Chemistry $B, 107,9441-9451$.

Boyac1, E., Eroğlu, A. E., \& Shahwan, T. (2010). Sorption of As (V) from waters using chitosan and chitosan-immobilized sodium silicate prior to atomic spectrometric determination. Talanta, 80, 1452-1460.

Chatterjee, S., \& Woo, S. H. (2009). The removal of nitrate from aqueous solutions by chitosan hydrogel beads. Journal of Hazardous Materials, 164, 1012-1018.

Chaunhan, D., Jaiswal, M., \& Sankararamakrishnan, N. (2012). Removal of cadmium and hexavalent chromium from electroplating waste water using thiocarbamoyl chitosan. Carbohydrate Polymers, 88, 670-675.

Chen, C. C., \& Chung, Y. C. (2006). Arsenic removal using a biopolymer chitosan sorbent. Journal of Environmental Science and Health Part A, 41, 645-658.

Chen, C. Y., Chang, T. H., Kuo, J. T., Chen, Y. F., \& Chung, Y. C. (2008). Characteristics of molybdateimpregnated chitosan beads (MICB) in terms of arsenic removal from water and the application of a MICBpacked column to remove arsenic from wastewater. Bioresource Technology, 99, 7487-7494.

Choong, T. S. Y., Chuah, T. G., Robiah, Y., Koay, F. L. G., \& Azni, I. (2007). Arsenic toxicity, health hazards and removal techniques from water: an overview. Desalination, 217, 139-166.

Dambies, L., Vincent, T., \& Guibal, E. (2002). Treatment of arsenic-containing solutions using chitosan derivatives: uptake mechanism and sorption performances. Water Research, 36, 3699-3710.

Elwakeel, K. Z. (2010). Environmental application of chitosan resins for the treatment of water and wastewater: a review. Journal of Dispersion Science and Technology, 31, 273-288.

Ersoy, B., Sariisik, A., Dikmen, S., \& Sariisik, G. (2010). Characterization of acidic pumice and determination of its electrokinetic properties in water. Powder Technology, 197, 129-135. 
Guibal, E., Milot, C., \& Tobin, J. M. (1998). Metal-anion sorption by chitosan beads: equilibrium and kinetic studies. Industrial and Engineering Chemistry Research, 37, 1454-1463.

Hansen, H. K., Nunez, P., \& Jil, C. (2008). Removal of arsenic from wastewaters by airlift electrocoagulation. Part 2: continuous reactor experiments. Separation Science and Technology, 43, 3663-3675.

Hasan, S., Ghosh, T. K., Viswanath, D. S., \& Boddu, V. M. (2008). Dispersion of chitosan on perlite for enhancement of copper (II) adsorption capacity. Journal of Hazardous Materials, 152, 826-837.

Huang, C. P., \& Fu, P. L. K. (1984). Treatment of Arsenic(V)containing water by the activated carbon process. Journal WPCF, 56, 233-242.

Kavcar, P., Sofuoglu, A., \& Sofuoglu, S. C. (2009). A health risk assessment for exposure to trace metals via drinking water ingestion pathway. International Journal of Hygiene and Environmental Health, 212, 216-227.

Kitis, M., \& Kaplan, S. S. (2007). Advanced oxidation of natural organic matter using hydrogen peroxide and iron-coated pumice particles. Chemosphere, 68, 1846-1853.

Kitis, M., Karakaya, E., \& Yigit, N. O. (2005). Heterogeneous catalytic degradation of cyanide using copper-impregnated pumice and hydrogen peroxide. Water Research, 39, 16521662.

Kundu, S., Kavalakatt, S. S., \& Pal, A. (2004). Removal of arsenic using hardened paste of Portland cement: batch adsorption and column study. Water Research, 38, 3780-3790.

Luu, T. T. G., Sthiannopkao, S., \& Kim, K. W. (2009). Arsenic and other trace elements contamination in groundwater and a risk assessment study for the residents in the Kandal Province of Cambodia. Environmental International, 35, 455-460.

Maliyekkal, S. M., Philip, L., \& Pradeep, T. (2009). As (III), removal from drinking water using manganese oxide-coated-alumina: performance evaluation and mechanistic details of surface binding. Chemical Engineering Journal, 153, 101-107.

Miretzky, P., \& Cirelli, A. F. (2009). Hg (II) removal from water by chitosan and chitosan derivatives: a review. Journal of Hazardous Materials, 167, 10-23.
Mohan, D., \& Pittman, C. U., Jr. (2007). Arsenic removal from water/wastewater using adsorbents - a critical review. Journal of Hazardous Materials, 142, 1-53.

Panuccio, M. R., Sorgona, A., Rizzo, M., \& Cacco, G. (2009). Cadmium adsorption on vermiculite, zeolite and pumice: batch experimental studies. Journal of Environmental Management, 90, 364-374.

Quintelas, C., Rocha, Z., Silva, B., Fonseca, B., Figueiredo, H., \& Tavares, T. (2009). Removal of Cd (II), Cr (VI), Fe (III) and $\mathrm{Ni}$ (II) from aqueous solutions by an E. coli biofilm supported on kaolin. Chemical Engineering Journal, 149, 319-324.

Rau, I., Gonzalo, A., \& Valiente, M. (2003). Arsenic (V) adsorption by immobilized iron mediation. Modeling of the adsorption process and influence of the interfering ions. Reactive and Functional Polymers, 54, 85-94.

Schijf, J., \& Ebling, A. M. (2010). Investigation of the ionic strength dependence of Ulva lactuca acid functional group $\mathrm{pK}_{\mathrm{a}} \mathrm{s}$ by manual alkalimetric titrations. Environmental Science and Pollution Research, 44, 1644-1649.

Şeker, A., Shahwan, T., Eroğlu, A. E., Yılmaz, S., Demirel, Z., \& Dalay, M. C. (2008). Equilibrium, thermodynamic and kinetic studies for the biosorption of aqueous lead (II), cadmium (II) and nickel (II) ions on Spirulina platensis. Journal of Hazardous Materials, 154, 973-980.

Tolaimate, A., Desbrieres, J., Rhazi, M., Alagui, A., Vicendon, M., $\&$ Vottero, P. (2000). On the influence of deacetylation process on the physicochemical characteristics of chitosan from squid chitin. Polymer, 41, 2463-2469.

Viswanathan, N., Sundaram, C. S., \& Meenakshi, S. (2009). Removal of fluoride from aqueous solutions using protonated chitosan beads. Journal of Hazardous Materials, 161, 423430.

Yavuz, M., Gode, F., Pehlivan, E., Ozmert, S., \& Sharma, Y. C. (2008). An economic removal of $\mathrm{Cu}^{2+}$ and $\mathrm{Cr}^{3+}$ on the new adsorbents: pumice and polyacrylonitrile/pumice composite. Chemical Engineering Journal, 137, 435-461.

Zhang, S., Guo, Z., Xu, J., \& Niu, H. (2011). Effect of environmental conditions on the sorption of radiocobalt from aqueous solution to treated eggshell as biosorbent. Journal of Radioanalytical and Nuclear Chemistry, 288, 121-130. 